\title{
Electrochemical Study on Corrosion Resistance of Epoxy- Coated Reinforcing Steel in Bridge Concrete
}

\author{
Yongcun Zhang
}

School of Civil and Transportation Engineering, Henan University of Urban Construction, Pingdingshan, 467036, Henan, China

E-mail: zycpds001@163.com

doi: $10.20964 / 2019.09 .85$

Received: 3 May 2019 / Accepted: 1 July 2019 / Published: 5 August 2019

Chloride infiltration is one of the major causes for bridge damages in regions where deicing salts are used. In this study, the role of epoxy-coated steel reinforcement in concrete to prevent corrosion is evaluated. Electrochemical impedance spectroscopy (EIS) testing was performed between the embedded steel by applying different potentials at various frequencies to evaluate the chloride ion effect and coating condition. The value of impedance at $1 \mathrm{mHz}$ shows that epoxy-coating has a major influence on impedance values. This behaviour may be due to the combination of coating and corrosion related impedance factors. On comparison, it was found that polarization resistance data and the impedance values measured at the low frequency of $0.001 \mathrm{~Hz}$ for epoxy-coated reinforcing specimens were linear. These results indicated that epoxy-coated rebar increased the corrosion protection against chloride infiltration.

Keywords: Epoxy-coated reinforcing steel; Concrete bridge desks; Electrochemical impedance spectroscopy; Chloride ion effect

\section{FULL TEXT}

(C) 2019 The Authors. Published by ESG (www.electrochemsci.org). This article is an open access article distributed under the terms and conditions of the Creative Commons Attribution license (http://creativecommons.org/licenses/by/4.0/). 